\title{
Monitoring Energy Level of Smart Energy System for Home Appliances
}

\author{
M. Rupesh ${ }^{1}$, Dr.N.Anbu Selvan ${ }^{2}$, \\ \{roopeshroop97@gmail.com ${ }^{1}$, anbu.1324@gmail.com ${ }^{2}$ \}
UG Scholar ${ }^{1}$, Department of Electrical and Electronics Engineering, Saveetha School of Engineering, Saveetha Institute of Medical And Technical Science, Chennai
Assistant Professor ${ }^{2}$, Department of Electrical and Electronics Engineering, Saveetha School of Engineering, Saveetha Institute of Medical And Technical Science, Chennai

\begin{abstract}
There is a continues change and modification in communication technology. Earlier days customers know about their energy consumption only when a member for EB takes the readings. But now the technology has been changed. The method we have proposed here is based on IOT system. The smart meter is connected to the customer's phone number. When the usage of current is more the customer gets an alert message to the particular registered number. Their bill for the current consumption is send to the registered number. If the customer didn't pay the bill their supply of current will be blocked to the particular house. This technology reduces the man power and time. Earlier it is difficult to upload the customer's fee in the website, but this technology which has been implemented directly uploads the bill in the website and displayed to the user through SMS. These are the smart devices used to manage and record electricity of electronic devices. This device monitors the electric system in real time. It also has the ability to get lower electricity bills. When the user exceeds the limit, this proposed system automatically issues an alarm to the consumer. Smart meter is constructed by using Ardunio micro controller, current senor and voltage sensor.
\end{abstract}

Keywords: Energy Meter, IoT, Sensor, Current Sensor, Voltage Sensor.

\section{Introduction}

In current situation the entire world is facing energy problem. Electricity is the most important basic requirement of human beings. It is mainly used in houses, manufacturing organizations and farming industries. Electric meter is the important component to measure the amount of current used. Traditional meters are used to measure only the amount of units consumed by the user. This system does not provide any warning message to user when the user crosses the threshold level. The main problem in the traditional meter is to collect the reading from the users place. Using existing system the meter reading is collected by manually. It leads to various corruption activities and human error also occur. The main disadvantage of the existing system is to wastage of human energy. To avoid the above mentioned problems IoT based smart meter is used measure the usage of current. It also provides an alarm to the user when the users cross the maximum level. This meter generates a SMS and E-Mail when after generating bill. This new system also provides two way communication facilities.

The important features of this proposed smart meter are 
- Measure the current consumption level automatically with the help of various sensors

- Creates an alarm when the user cross the limit

- Entire system is controlled from remote location

The second section of this paper reviewed about various smart meters. Third section explains the proposed architecture of smart meter. Section four deals with sample output of proposed system. Finally fifth section concludes the system.

\section{Literature Survey}

Geetha.R M.E et al., says about the various problems in traditional electric meter. Measuring and monitoring electricity consumption is very difficult process in current situation. Now the people from EB comes and measures the energy consumption level and update the collected information into the server. Based upon the unit consumed the electric charge is collected from the user. Here the authors construct a new system to measure the current readings automatically with the help of internet. This proposed system is constructed by using Arduino controller. This system measures the consumed level and transfers the units via internet with the help of WiFi communication. By using this system the user can easily check the current usage with charge in online. The above details are displayed on the user's webpage itself. This system cost is less compared with other ordinary meters and this system also prevents the electrical equipments from repair. [1]

M. M. Mohamed Mufassirin et al., discussed about how to identify electrical theft. Many countries collect the information about the current usage and finding illegal electricity usage is very critical. It takes large amount of time and human resources. To overcome this issues the authors proposed a new system for reading current and monitory the meters by using IoT. This new system is very efficient and low cost way to send the data of current consumed to the authorized people. It also provides the service to find the illegal way to use the electricity. The main aim of this system is monitory the current consumption level in houses and crease a EB bill in automatic manner using current communication technology IoT. This system is also used to find the current theft and control it. Arduino microcontroller is control the entire system and to make the connection to wifi network, server. Infrared sensor is used to detect the illegal activities in the current meter. If the system found any illegal activities in the electric meter automatically the server disconnect the power supply. The automation facility decreases the human man power [2].

$\mathrm{N}$ M Yoeseph et al., discussed about the usage of energy meter. This device is an electrical instrument used to measure the current consumption level and to calculate the amount based upon usage of current. This paper presents a new system; it is used to measure current consumption reading using current sensor, voltage sensor and IoT server. The entire system is controlled by arduino microcontroller. The energy meter LCD display used energy units and EB bill. The alter message of current usage or EB amount can be created and displayed to the user [3].

M. Prathik ET AL., explained about the importance of electricity. In this digital world electricity is the important key factor of human life. Due to the growth of communication technology IoT based devices are created as a new revolution in communication world. The 
important aim of this proposed project is to generate alertness about usage of energy and for save energy. In traditional electric billing system have lot of demerits. This new system provides current consumption level and generates a bill automatically. This system also issues an alarm sound when the user can cross the limit. Most of the human errors are reduced when using this proposed system. It is very helpful to the common people for conserve energy. If user does not pay the EB bill on time, this system automatically disconnect the power supply [4].

Amrita Singh et al., designed a new device for measure energy consumption rate without human intervention. Iot is the new communication concept; it creates a link between various physical devices such as sensors, controllers and software. This new automatic device is used to collect the data from the consumers and send the data to the server for billing purpose. This system is used to collect correct reading, generate the EB bill properly and immediately send the message to the consumers [5].

Mr. Samarth Pandit et al., explained about the disadvantages of existing energy meter. In this paper the authors proposed a new device to measure the energy level. This new system is helpful in various ways likes decrease energy consumption level and measure the number of units consumed by the user. This new system is designed by using Arduino device, sensors and IoT concepts. In case of any illegal activates are occurring in meter the power supply will removed automatically [6].

Syed Mustafa et al., describes about smart energy meter using sensors, micro controller with IoT concepts. This energy meter is reduced the human interventions during meter reading. The EB bill also generate automatically bill and send to the user immediately. The entire information will be displayed on the user web page for their reference. . WiFi module do the IoT operations by transfer energy data to the users web page. The web page is accessed by the specific IP address. To construct this system various hardware and software modules are used. Sensors and used to sense the surrounding values and send to the server immediately for further processing [7].

A.Subba Rao et al., proposed a new framework of measure and control the energy on current meters. The current consumption is also collected from remote locations. This proposed frame work send the current consumption value to the user automatically with the help of GSM concept. The SMS alert message is also receive from the administrator to the consumers automatically. Frame work is developed based on ARM controller and it is utilized various sensor values [8].

ManasaNagesh et al., discussed about the current scenario of measuring electricity. Now a person come to the users house and measure the current usage level manually. Based upon the usage level the consumers pay the EB bill. The main disadvantage of this traditional system is the EB peoples go to the specific area directly, measure the current usage, generate the bill and transfer to the user. During this process various human errors will occur. To overcome these issues the authors proposed a new smart device using Arduino controller. This proposed device is embedded with the existing meter. GSM module is used to send the SMS to the user [9]. 


\section{Proposed Method}

Electricity is playing a major role in every human life. Using traditional meters the people directly come to the consumers place and take the readings. Based upon the consumed level the bill is generated. The proposed device is used to monitor the current usage level and send the consumed level to the users immediately. This smart system is constructed with the help of Arduino controller with WiFi module. Using this system user can get the sms message and check the usage of the current level from anywhere in the country with the help of WiFi module. Smart meter is constructed by using various sensors. Current sensor (ACS712 Current Sensor) is used to observe the energy usage level. The important usage of the current sensor is it measures AC and DC current. The following figure 1 shows the block diagram of our proposed system.

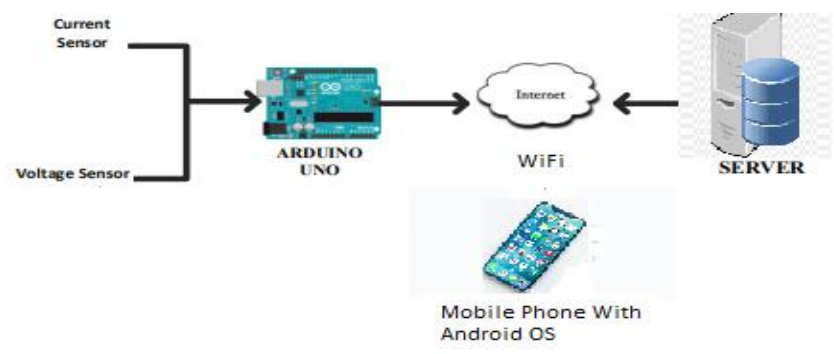

Fig1 Block Diagram of Proposed System

The traditional meter needs number of labors for measuring current consumption. But this device is used to measure the current usage level automatically, calculate the bill based upon usage level and send to the user immediately with the help of various sensors. This smart meter save our home from bad current condition and provides the alert message to the consumer when the current consumption level exceeds the threshold value. Ardunio based controller is used to develop the real time projects. The connection is cut off when the voltage level exceeds the limit. So electrical appliances are saved from being damage due to high voltage.

\section{Results And Discussions}

This proposed smart meter is used to measure the current consumption level automatically with the help of current communication technologies. IoT plays a major role in all areas. Smart meter is also constructed with the help of various sensors and controller. The controller controls the entire functions of the system. Smart energy meter provides an alert message to the consumers when the usage level crosses the limited level. The following message is displayed when the user exceeds the limited level. 


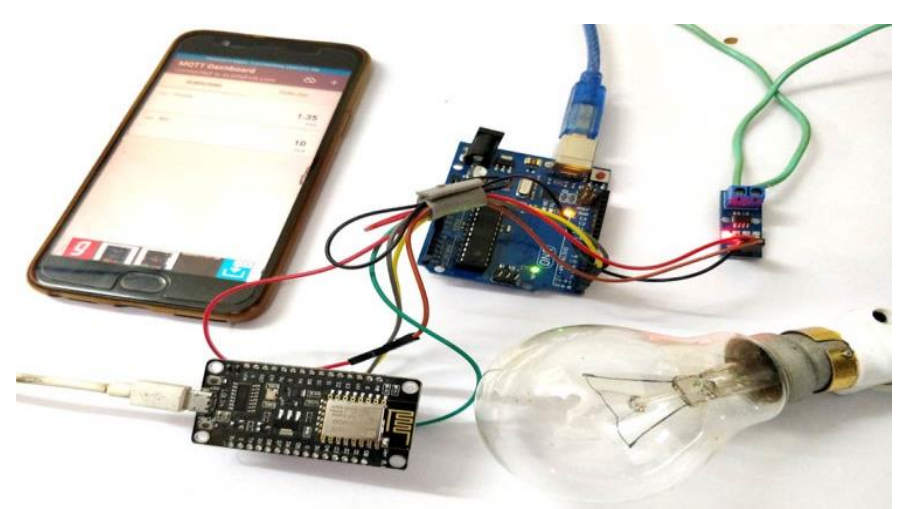

Fig 2: Hardware setup of smart meter

The usage level is measured automatically and generates the bill. The generated bill sends to the user's mobile phone and their websites. The users can see their bill amount and the usage of the current level from anywhere at any time. The following message is to be send to the user after measuring the consumption level.

\section{Conclusion}

Energy meter is one of the important components in our day today life. In traditional meter all the activities are done manually. Due to this reason various types of errors are occurred. To avoid such kind of problem smart meter is introduced. This smart energy meter is used to measure the energy level regularly. It is assist to decrease the energy consumption level by compare with daily usage level. The major benefit of this proposed system is to reduce the human energy to measure the current reading monthly. The alarm will help the consumers to develop a consciousness to the people regarding current usage level. It also reduces the energy wastage level and the websites display the details in regular basis. The user can able to check the details from anywhere in the world. Sensors are used to measure the current and send to the server for billing purpose. The whole system is controlled with the help of microcontroller.

\section{References}

[1] S. K. Shukla (2014), "2014 Real-Time Monitoring System for Landslide Prediction Using Wireless Sensor Networks “, International Journal of Modern Communication Technologies \& Research (IJMCTR) ISSN: 2321-0850, Vol. 2, No. 12, pp. 14-19.

[2] Niraj Prasad Bhatta \&Dr.Thangadurai.N(2017), "A Review on Environmental Sensors Used For Landslide Prediction And Detection “, Journal of Environmental Engineering and Studies, Vol. 2 , No. 2, pp. 1-8.

[3] K Sundaraganapathy, S. Nirmala SugirthaRajini\& S Ramamoorthy(2017), "Embedded lockets for multipurpose tracking system using GPS GPRS and GSM", Indian J. Science and Technology 10 (3), pp.1-5. 
[4] Govind Singh Bhardwaj, MayankMetha, Md. Yeasin Ahmed, Mohammod\&Aktarul Islam Chowdhury(2014), "Landslide monitoring by using sensor and wireless technique: a review "International Journal Of Geomatics And Geosciences, Vol. 5, No 1, ISSN 0976 - 4380 , pp. 1-7.

[5] Anitha K \& Ravi S(2016), "An Overview of Landslide Forecasting Using Wireless Sensor Network and Geographical Information System", Journal of Engineering Research and Applications, ISSN: 2248-9622, Vol. 6, Issue 4, pp.70-75.

[6] Kim \&Hyoung Woo(2016), “ Development of Wireless Sensor Node for Landslide Detection”, Proceedings of the APAN - Research Workshop, pp. 56-60.

[7] Gang Qiao , Ping Lu , Marco Scaioni, Shuying Xu , Xiaohua Tong , Tiantian Feng , Hangbin Wu , Wen Chen , Yixiang Tian , Weian Wang \&Rongxing Li (2013), "Landslide Investigation with Remote Sensing and Sensor Network: From Susceptibility Mapping and Scaled-down Simulation towards in situ Sensor Network Design", Remote Sensing, ISSN 2072-4292, pp.43194346.

[8] N. Dixon, A. Smith, J. A. Flint, R. Khanna, B. Clark \& M. Andjelkovic(2018), "An acoustic emission landslide early warning system for communities in low-income and middle-income countries", pp. 1631-1644, Springer.

[9] Th.Nanao\&RomeshLaishram(2019), "Integrated Earthquake and Landslide Monitoring Over Wireless Sensor Network", International Journal of Recent Technology and Engineering (IJRTE), ISSN: 2277-3878, Vol.8 No. 4, pp. $9594-9599$.

[10] Meryem El Moulata, Olivier Debaucheb,c, Sä1dMahmoudib, LahcenÄitBrahima\& Pierre Mannebackb(2018), "Monitoring System Using Internet of Things For Potential Landslides Monitoring System Using Internet of Things For Potential Landslides", The 15th International Conference on Mobile Systems and Pervasive Computing Procedia Computer Science 134, pp. 26 34.

[11] Maneesha\& V. Ramesh(2009)," Real-time Wireless Sensor Network for Landslide Detection", Third International Conference on Sensor Technologies and Applications, pp 505-409. 